\title{
APORTES DE JEAN PIAGET A LA TEORÍA DEL CONOCIMIENTO INFANTIL
}

\author{
Manuel Arboccó de los Heros*
}

\begin{abstract}
Resumen
En el presente trabajo mencionaremos brevemente una de las más grandes contribuciones hechas a la psicología cognitiva infantil por parte del biólogo y epistemólogo Jean Piaget. Conceptos como asimilación, adaptación, esquemas y operaciones mentales son parte de su abundante teoría, la cual nos permite explicar de manera lógica y documentada cómo atraviesan los niños una serie de experiencias cognitivas por influencia del componente social así como por las tendencias propias de la maduración biológica que le permiten avanzar en su desarrollo mental, desde periodos de contacto sensorial con los objetos hasta el empleo del pensamiento formal y abstracto.
\end{abstract}

Palabras clave: asimilación, acomodación, esquemas mentales, sensorio motor, permanencia del objeto, adaptación, maduración, desarrollo.

\begin{abstract}
During the current work, we will briefly mention one of the most important contributions made to the Child Cognitive Psychology by the biologist as well as epistemologist Jean Piaget. Concepts as assimilation, adaptation, schemes and mental operations are part of the wide theory, which allow us to explain with logic and background how child face a series of cognitive experiences by the influence of the social component as well as the own tendencies of the biologic maturing which allow to advance in the mental development, since the sensorial contact period with objects until the use of the formal and abstract thinking.
\end{abstract}

Key words: assimilation, accommodation, mental schemes, sensory motor, object continuance, adaptation, maturation, development.

\footnotetext{
* Licenciado en Psicología. Docente en Psicología en la Universidad Femenina del Sagrado Corazón (UNIFÉ) y la Universidad Inca Garcilaso de la Vega (UIGV). Estudios de Maestría en Psicología con mención en Psicología Educativa por la Universidad NacionalMayor de San Marcos (UNMSM). manoloarbocco@gmail.com
} 


\section{EL DESARROLLO COGNITIVO PARA JEAN PIAGET}

Una de las teorías más difundidas acerca del desarrollo del conocimiento es la de Jean Piaget (18961980). En su enfoque describió el conocimiento de acuerdo con tres conceptos básicos: 1 . Esquemas generales; 2. La asimilación; y 3. La acomodación.

En cuanto a los esquemas mentales se trata de la primera unidad cognoscitiva del niño pequeño. El esquema es el modo que tiene la mente de representar los aspectos más importantes o rasgos esenciales de cierto acontecimiento. Para Piaget (1989) toda conducta de los organismos, trátese de un acto desplegado al exterior o al interior, se presenta como una adaptación del individuo al medio. Ello comprende los procesos de asimilación al medio.

En la asimilación el individuo incorpora funcionalmente aspectos del medio y actúa sobre él, para transformarlo; en la acomodación el individuo por el contrario, se adecúa a la influencia del medio para lo cual el organismo tiene que transformarse (Piaget, 1964).

Piaget postula que la adaptación es el esfuerzo cognoscitivo del organismo para hallar un equilibrio entre él mismo y su ambiente, y ello depende de la asimilación y la acomodación. Estos mecanismos permiten al niño avanzar desde una etapa hasta la siguiente. La asimilación sería pues la tendencia a relacionar un nuevo acontecimiento con una idea que uno ya posee. Se trata, en definitiva; de que el niño adapte el ambiente a sí mismo, a su propia estructura mental. Mediante la acomodación el niño cambia las ideas propias para que puedan coincidir con un acontecimiento nuevo inicialmente desconcertante. Este proceso representa la influencia del ambiente real. Ambos procesos, asimilación y acomodación actúan generalmente siempre juntos.

Por otro lado, Jean Piaget (2001) indica que si bien el conocimiento es un componente importante en la psicología de una persona, el otro componente es el afecto. Obviamente hizo una distinción: el afecto aporta "la fuerza motora dinámica", esto puede entenderse como el interés, la motivación para hacer una cosa en lugar de otra, para aprender algo o no. Nos recuerda que las dos funciones fundamentales del niño (intelecto y afecto) son como las dos caras de una moneda, ambas contribuyen a la adaptación al ambiente. Su teoría descansa en el supuesto de que la personalidad humana se desarrolla a partir de funciones intelectuales y afectivas y de la interrelación de las dos funciones. Todos los atributos de la personalidad, según Piaget, dependen esencialmente de la capacidad intelectual del individuo para organizar su experiencia.

También realiza un distingo importante entre la maduración y el desarrollo, términos comúnmente empleados como sinónimos. Llamó maduración al crecimiento fisiológico y desarrollo al crecimiento psicológico, y fue el desarrollo el tema básico de sus estudios e investigaciones.

Indica que en toda conducta hay algún conocimiento subyacente. Distingue entre contenido y forma. El contenido (información, estímulo) se deriva del hecho particular al que va dirigido el conocimiento en tanto que la forma (significado, entendimiento) se deriva de la estructura interna. El contenido es frecuentemente observable, la forma no. Para Piaget (1964) la totalidad de los esquemas (la capacidad interna del organismo para asimilar), de que dispone una persona forman su inteligencia.

El desarrollo es una reestructuración progresiva y resulta de la paulatina adquisición de nuevas capacidades (Flavell, 1995). Lo que no es observable ahora, será visto más adelante, durante la vida futura del niño.

Para el cientíico suizo el desarrollo es un proceso inherente, inalterable y evolutivo, distinguiéndose por una serie de cuatro fases o estadios, estos son:

\section{Período sensorio motor o sensorio motriz}

Esta etapa abarca desde el nacimiento hasta los 24 meses de edad aproximadamente. Al nacer el infante no se percata del yo (sujeto) tampoco del no yo (objeto). En ese momento el mundo es una experiencia indiferenciada del presente, sin espacio, sin tiempo y sin objetos. El punto de partida lo constituyen estos modelos innatos de conducta: succión, prensión y una tosca actividad corporal.

El desarrollo durante esta fase implica la adquisición de destreza perceptiva en la utilización sobre el mundo exterior y de destreza motora en la manipulación del entorno. El infante adquiere 
conocimiento sensorio motor experimentando el medio. Comienza a coordinar sus diferentes experiencias sensoriales. Un principal logro de esta etapa es mantener la permanencia del objeto que es la capacidad que tiene el niño para considerar que un objeto que ha estado dentro de su campo visual no desaparece cuando sale de éste.Así los pequeños saben que las cosas existen independientemente de su acción actual. Este es un primer paso en el conocimiento conceptual puesto que las cosas no sólo son cosas de acción sino que empiezan a ser conceptos (objetos de conocimiento).

Según Piaget, la palabra sensorio motriz indica que el niño crea un mundo práctico totalmente vinculado a sus deseos de satisfacción física en el ámbito de su experiencia sensorial inmediata. Las tareas fundamentales de desarrollo de este periodo son la coordinación de las actividades motoras y la percepción o senso-percepción en un todo (Flavell, 1995).

\section{Período pre operacional o preoperatorio}

La formación de objetos de conocimiento (conceptos) deviene en la etapa preoperatoria. Esta fase se inicia a los dos años y culminará a los siete años aproximadamente. El niño comienza a utilizar símbolos y a entretenerse con juegos imaginativos. Desarrolla el lenguaje y la habilidad para diferenciar entre las palabras y cosas que no están presentes. Según Piaget la formación del objeto (diferenciación) es el producto final de la etapa sensorio motora y de esta manera, los símbolos que usará el niño son dependientes del conocimiento previamente obtenido en la etapa sensorio motriz.

"El ser capaz de separar la cosa del objeto y de pensar en ella en su ausencia, le quita la seguridad del funcionamiento práctico y le hace vivir en un mundo simbólico de su propia construcción" (Furth y Wachs, 1978, p. 86). Es necesario recordar que el pensamiento del niño en este periodo es egocéntrico, es decir, que quiere explicarlo todo según su punto de vista ya que es imposible ponerse en el lugar de los demás; es artificioso ya que afirma que los fenómenos naturales son causados por la mano del hombre y es animista pues atribuye estados anímicos a las cosas (Piaget, 1969).

\section{Periodo de las operaciones concretas}

Comprende de los siete a los doce años aproximadamente. Aparecen las operaciones intelectuales. El niño es capaz de realizar operaciones de clasificación, conservación, seriación, correspondencias, esquemas espaciales y temporales, numeración, pero siempre y cuando tenga oportunidad de percibir y manipular el material concreto que se le presente. El pensamiento está aún limitado a lo concreto, a las características tangibles del medio. Por ejemplo: Ios niños pueden dar una solución matemática al problema: "enséñame por qué cuatro manzanas y tres manzanas son siete manzanas", porque las pueden ver, tocar y luego contar. Pero si se le pregunta al mismo niño: “¿por qué $4 x+3 x=7 x$ ?", se sentirá confundido ante tal abstracción.

Piaget (1991) considera que el niño de esta edad entra en la etapa de las operaciones concretas porque se ha conformado en él una organización cognoscitiva superior a las existentes en etapas anteriores. Pero todavía no podrá tratar con abstracciones, para lo cual recién será capaz en la próxima etapa.

\section{Período de las operaciones formales}

Se inicia alrededor de los doce años en adelante. En esta etapa se asiste a una independización de la percepción y por consiguiente la acción es completa. Caracteriza el pensamiento abstracto y formal. El ahora adolescente es capaz de pensar y considerar lo que está más allá del presente, de formular hipótesis y teorías de lo posible, de hacer razonamientos sobre la base de suposiciones meramente formales. Puede ya realizar inferencias lógicas sin necesidad de lo factual o concreto (Piaget y García, 1987). En el transcurso de esta etapa se capacita para trabajar con abstracciones, con posibilidades, tan efectivamente como hasta entonces sólo trabajaba con los objetos de la realidad. Por eso lo que caracteriza a este estadio es el método hipotético-deductivo; según el cual se establece una hipótesis o posibilidad (bajo tales o cuales condiciones) yse deduce el resultado (cómo sucederátal o cual cosa).

Este periodo se denomina formal porque se caracteriza por la habilidad que adquiere el sujeto para pensar en formas puras de pensamiento. El que llega a esta etapa será capaz de operar con este tipo de pensamiento formal y abstracto. Lo que no quiere decir que todos lleguen a ella. Algunos permanecen en la etapa anterior. 
Cada fase refleja una gama de pautas de organización, que se manifiesta en una secuencia definida dentro de un periodo de edad aproximado en el continuo desarrollo. Completar una fase da lugar a un equilibrio transitorio así como al comienzo de un nuevo desequilibrio que corresponderá a una nueva fase.

\section{COMENTARIO FINAL}

Para Jean Piaget la inteligencia es un proceso continuo de adaptación que comienza al nacer y que sigue una serie de fases o periodos básicos (1964, 1969, 1975). La inteligencia crece como un proceso de acumulación pero las nuevas experiencias no se insertan en la mente del niño fácilmente; se hace necesaria la existencia de conocimientos o experiencias previas con las cuales se transformarán mutuamente.

Son de mucha importancia los procesos de asimilación -incorporación y conexión de conocimientos del ambiente- y de acomodación -transformación de acuerdo a lo que el medio nos va presentando-

Existe una retroalimentación en este punto, ya que lo que voy conociendo me es útil en mi propio proceso adaptativo y a medida que mejor me adapte, podré asimilar más situaciones para su posterior interpretación (1986, 1989). Así la inteligencia es asimilación en la medida en que incorpora todos los datos de la experiencia dentro de su marco; asimila en su interior nuevas experiencias, transformándolas para que se puedan adaptar a la estructura construida.

Según Piaget el desarrollo psíquico que se inicia con el nacimiento y finaliza en la edad adulta, es comparable al crecimiento orgánico y al igual que este, consiste en una marcha hacia el equilibrio. Entonces el desarrollo es un progresivo equilibrarse, un continuo paso de un estado menos equilibrado a un estado superior de equilibrio. Además existen funciones constantes comunes a todas las edades pero lo que varía de un nivel mental a otro son los intereses.

Existen estructuras progresivas o formas sucesivas de equilibrio que van apareciendo según el grado de desarrollo intelectual, para el caso tratado. Cada una de las etapas evolutivas establecidas por Piaget (1964, 1969) se caracteriza por la aparición de estructuras originales, cuya construcción la distingue de las etapas anteriores.

Señala asimismo que toda necesidad tiende a incorporar las cosas y las personas a la actividad propia del sujeto, y por tanto a "asimilar" el mundo exterior a las estructuras ya construidas; $y$ a reajustar estas en función de las transformaciones experimentadas y por tanto a "acomodarlas" a los objetos externos. Se puede denominar adaptación al equilibrio de estas asimilaciones y acomodaciones.

Podría decirse que Piaget no confiere demasiada importancia al coeficiente de Inteligencia (C.I.) o puntuaciones obtenidas en tests para medir la inteligencia (que dicho sea de paso muchos han demostrado no ser muy fidedignos al tener reactivos muy circunscritos a una realidad, tiempo o población determinada), para hacer más bien hincapié en lo común o esperado de los seres humanos de acuerdo al avance por periodos de edad.

Si bien Jean Piaget rechazauna postura extremista entre la cuestión de lo "innato" y lo «aprendido" se debe considerar, con la información que actualmente tenemos, que así como el niño descubre por sí mismo, día a día, nuevas metas intelectuales, para este incremento necesita una relación activa, sobre todo positiva con el medio. Una realidad estimulante, protectora, digna de confianza. Sin un ambiente familiar que preste cuidados y apoyo, poco será el crecimiento de un niño tanto en su parte fisiológica (maduración) como en su parte psicológica (desarrollo).

Debe considerarse que en nuestra época se afirma que tanto los factores genéticos o hereditarios, así como el medio externo influyen notoriamente en las manifestaciones de la capacidad o potencial intelectual, así como en diversos rasgos de la personalidad en su conjunto. Los diversos estudios acerca de la herencia y la genética conductual han aportado resultados significativos en relación al efecto de las raíces genéticas en la inteligencia de los descendientes (Larsen y Buss, 2005). Paralelamente los avances en psicología social y psicología del desarrollo han demostrado que un ambiente social rico o estimulante, o por el contrario, un ambiente empobrecido, afecta directamente el rendimiento intelectual de niños y de los mismos adultos. Además, variados estudios han 
demostrado el efecto que tiene la estimulación temprana mediante la educación pre-escolar en el desarrollo cognitivo.

Finalmente, es útil recordar que el niño necesita de la interacción con personas y objetos a fin de sacar provecho de las nuevas aptitudes que la maduración neurológica hace posibles (Pérez Pereira, 1995). Esta estimulación psicoafectiva y física en la temprana infancia se traduce en un mayor nivel de maduración neurológica y, por lo tanto, en una mayor capacitación intelectual y perceptiva (Piaget, 1968).

\section{REFERENCIAS}

Flavell, J. H. (1995). La psicología evolutiva de Jean Piaget. México, D.F.: Paidós.

Furth, H. G. y Wachs, H. (1978). La teoría de Piaget en la práctica. Buenos Aires: Kapeluz.

Larsen, R. y Buss, D. (2005). Psicología de la personalidad. Dominios de conocimiento sobre la naturaleza humana. México: McGraw-Hill Interamericana.
Pérez Pereira, M. (1995). Nuevas perspectivas en psicología del desarrollo. Madrid: Edit. Alianza.

Piaget, J. (1964). Seis estudios de Psicología. Barcelona: Seix-Barral.

Piaget, J. (1968). Educación e instrucción. Buenos Aires: Proteo.

Piaget, J. (1969). El nacimiento de la inteligencia en el niño. Madrid: El Aguilar.

Piaget, J. (1975). Psicología y epistemología. Barcelona: Editorial Ariel.

Piaget, J. (1986). La epistemología genética. Madrid: Editorial Debate.

Piaget, J. (1989). Adaptación vital y psicología de la inteligencia. México: Editorial Siglo XX.

Piaget, J. (1991). La formación del símbolo en el niño. Buenos Aires: Fondo de Cultura Económica.

Piaget, J. (2001). Inteligencia y afectividad. Buenos Aires: Aique.

Piaget, J. y García, R. (1987). Lógica y epistemología genética. Hacia una lógica de las significaciones. España: Edit. Gedisa. 